\title{
Assessment of Gender Disparity in Academic Performance Among Undergraduates of College of Medicine and Health Sciences, Ambo University, Ethiopia
}

\author{
Gerbaba Guta \\ Department of Public Health, Ambo University, College of Medicine and Health Sciences \\ P.O.Box: 19, Ambo, Ethiopia
}

\begin{abstract}
Introduction. Gender disparity in higher educational institutions of Ethiopia has become one of the cross cutting agendas that need special concern. The objective of this study was to assess gender disparity in academic performance among undergraduate students of Ambo University, College of Medicine and Health Sciences.

Methods. This paper analyzed the university entrance examination score and Cumulative Grade Point Average (CGPA) of 133 (92 male and 41 female) undergraduate graduates of 2017 at Ambo University, College of medicine and health sciences. The census survey was conducted through an anonymous self administered questionnaire from September 20-October 10, 2017. Independent sample t-test was performed to test gender disparity among the undergraduates with regard to academic performance.

Results. The study findings revealed that, there were gender disparities among undergraduates of Ambo University, College of Medicine and Health Sciences. Female students joined the University with lower university entrance examination score (Mean=428.5, $\mathrm{SD}=27.1$ ) compared to males (Mean=442.6, $\mathrm{SD}=25.2$ ). Thus, their grade 12 exam achievement mean difference was found to be statistically significant (Mean difference $=14.1 ; 95 \% \mathrm{CI}=4.52$ 23.67; $\mathrm{t}=2.913, \mathrm{df}=131, \mathrm{p}$-value=0.004). Similarly, female undergraduates achieved lower CGPA $(\mathrm{Mean}=2.93$, $\mathrm{SD}=0.39$ ) than male undergraduates $(\mathrm{Mean}=3.29, \mathrm{SD}=0.41$ ). There was also a significant mean difference between male and female students in CGPA achievement at university (Mean difference $=0.36$; 95\% CI $=0.21$ $0.51 ; \mathrm{t}=4.780, \mathrm{df}=131, \mathrm{p}$-value $<0.001)$. Moreover, the proportion of females graduated from the college in 2017 was only $26.5 \%$.

Conclusion. According to the students' high school performance, female students achieved university entrance examination score significantly lower than males. Similarly, female students' academic performance at university was also low compared to male students. Regarding gender composition graduates, the result indicates that female undergraduates were underrepresented in the college accounting only $26.5 \%$. The implication of this study suggests that the affirmative action intervention including tutorial classes, study skills, time management trainings and counseling provided to female students in the university was not effective since it couldn't eliminate gender gap in academic performance.
\end{abstract}

Keywords: Academic performance; Gender disparity assessment; independent t-test.

DOI: $10.7176 /$ RHSS/9-5-04

Publication date:March $31^{\text {st }} 2019$

\section{Introduction}

Currently, gender disparity in academic performance has got special attention in Ethiopia. Higher education is among the areas where highest gender gaps such as enrollment rate, academic achievement, graduation rate, and employment rate are reflected. To combat the problem, affirmative programs for female university students have been implemented in the country.

\subsection{Gender Disparity in Enrollment and graduation Rate}

Gender disparity in enrollment is common in Ethiopia at different education levels. Astonishingly, the gap becomes wider in higher education institutions compared to preparatory and secondary schools. According to FDRE Ministry of education's enrollment statistics report among undergraduate regular programs of the government institutions in 2015/16 out of a total of 379,389 enrollments, females accounted only 126,673 $(33.4 \%)$ ( Federal Democratic Republic of Ethiopia Ministry of Education, 2015/16).

Multiple factors were reported in different researches for lower proportion of female students joining universities in Ethiopia. Among these, long-standing cultural misconception of the community and the family about females' education causing early and forced marriage, demand of parents on their girls' labor due to economic problem and / or fail to cover costs for stationery and food were the major causes for females' low enrollment rate(Federal Democratic Republic of Ethiopia Ministry of Education, 2010; Olkaba, 2013). Some studies showed that traditional and cultural beliefs reinforce gender stereotypes that give preference to boys over girls in access to education (Federal Democratic Republic of Ethiopia Ministry of Education,2010; Swedish Agency for Development Evaluation Reports, 2010; Dea, 2016). 
In Ethiopia Universities, due to different factors low proportion of female students' enrollment has been observed. The most frequently mentioned factors are economic problem, failure of educational institutions in providing special support to females, promoting gender equality, protecting them from sexual harassment and lack of commitment in implementing affirmative action strategies. Moreover, remarkable number of female students is subjected to drop out since they are less likely to be successful in their academics coping with these situations (Federal Democratic Republic of Ethiopia Ministry of Education, 2010; Olkaba, 2013; Mersha, Bishaw \& Tegegne, 2013; Tiruneh \& Petros, 2014). Therefore, because of these major factors female graduates' rate remains low in Ethiopia higher educational institutions.

\subsection{Gender Disparity in Academic Performance}

Inconsistent gender disparity patterns were reported in researches done in different higher institutions regarding academic performance. Accordingly, several studies found that female students were significantly better than males in academic performance (Obadaki \& Omowumi, 2013; Zainal, Yahya \& Rahman, 2104; Khan \& Nawaz, 2012; Ahmad, Pervaiz \& Aleem, 2015; Madara,2016; Tarabashkina \& Lietz, 2011). In contrast, remarkable number of studies shows that non-significant difference in academic achievement between male and female graduates (Puju \& Netragaonkar, 2014; Okafo, 2011; Farhan \& Khan, 2015; Núñez-Peña \& Suárez-Pellicioni, 2016). However, in Ethiopia where families are eager to prepare their sons and daughters for different roles and expectations, female students' participation and academic achievement is consistently lower than that of males. For instance, some researchers reported the result that reveals male undergraduate graduates achieved significantly higher CGPA than females (Olkaba, 2013; Eshetu, 2015; Yigermal, 2017).

Therefore, inconsistent gender disparity pattern in academic performance reported by different studies cannot be explained by cognitive ability inefficiency and/or efficiency. A study done by Fergusson and Horwood (1997) showed that there is no significant difference in cognitive ability measured by intelligence quotient (IQ) scores between male and female. Therefore, there should be other alternative factors rather than cognitive ability that cause gender disparity in academic performance in undergraduate graduates who were subjected to the same environmental constraints.

Thus, the higher rate of educational under-achievement in males was adequately explained by gender related differences in classroom behaviors. More explicitly, males are becoming more prone to disruptive and inattentive classroom behaviors that appeared to impede male learning and lead to a male educational disadvantage (Fergusson and Horwood, 1997; Kenney-Benson \& Pomerantz, 2006; Islam, 2014). Whereas, in the case of Ethiopia higher education institutions different studies done on factors affecting female students' academic achievement showed that female students' academic achievement is lower than that of males due to female students' low self perception, sexual harassment, economic problem, lack of implementation of higher education policies and strategies and lack of proper guidance and support from the universities (Mersha, Bishaw \& Tegegne, 2013; Tiruneh \& Petros, 2014; Tenaw, 2018; Federal Democratic Republic of Ethiopia Ministry of Education, 2014; Mamo, Gosa \& Hailu, 2017). Studies further revealed that community's gender biased expectation about students academic performance has been affecting female students' education attainment. According to study done by Mamo, Gosa and Hailu (2017), most female students participated in the study agreed that their performance was affected by socio-cultural factors.

In numerous studies, other factors that affect academic performance were also identified. A study done among medical students revealed that stress had a negative impact on academic performance of students (Melaku, Mossie $\&$ Negash, 2015). Directly or indirectly, female students are more susceptible to stress than males. According to Silva and Hill (as cited in Kheswa, 2014 ), the effects of sexual harassment ranges from stress related symptoms such as loss of memory to self blame, lack of trust and concentration in class. Therefore, due to sexual harassment, female students may perform lower than male students since they loss interest and concentration in academic work.

In addition, researches have shown that student's motivation and student's academic performance has direct relationship where students who are more motivated perform better and a student who performs better become more motivated (Afzal, Ali, Khan \& Hamid,2010). This implies that, in the culture and norms where male dominance in education is acceptable, female students rarely motivated as male students. Therefore, less motivation in academic work directly affects female students' academic achievement. Moreover, less motivated students in learning are highly likely to spend shorter time in reading academic courses. As revealed by Issahaku (2017), the amount of time spent in reading had strong correlation with student's academic attainment.

Student's high school academic background can affect their academic performance at university. Studies done on determinants of academic performance of students showed the existence of a significant direct relationship between academic background measured by university entrance score and academic achievement at university (Afzal, Ali, Khan \& Hamid, 2010; Gardy \& Akbay, 2015; Muhammedhussen, 2016). Consequently, female students joining universities relatively with lower entrance score may suffer more from low self perception about their ability than male students. Therefore, impact of low self perception of female students about their ability further affects their motivation for academic work will result in achieving lower than male students (Tiruneh \& Petros, 2014; Tenaw, 2018). 
Assessing gender disparity in academic achievement and graduation rate is important because of the fact that graduation rate and educational attainment have an impact on entrance and competition in labor market. For instance, out of 73,689 undergraduate graduates of 2015/16, there were only 22,725 (30.8\%) females (Federal Democratic Republic of Ethiopia Ministry of Education, 2015). Gender disparity in academic achievement directly affects the participation of women in professional sectors especially in higher education teaching and educational leadership where minimum required CGPA is 2.75 for teaching staff. According to FDRE Ministry of Education, the proportion of women staff in higher education institutions of the country in 2015 was $12.5 \%$ excluding expatriate (Federal Democratic Republic of Ethiopia Ministry of Education, 2015). If gender disparity in academic performance is not solved, women participation remains underrepresented in different professional sectors.

Post-entry affirmative action for university female students including tutorial classes, life skills training, study skills training, time management training, counseling and career guidance services has been implemented in all public universities of Ethiopia to enhance survival rate of female students (Federal Democratic Republic of Ethiopia Ministry of Education, 2014). However, the effectiveness of the program was not evaluated in terms of academic achievement.

Most of the previous studies that have addressed gender disparity in academic performance of undergraduates have limitations. For instance, some studies were restricted to non-graduating classes academic performance without taking the students' academic performance change over time in to consideration (Mersha, Bishaw \& Tegegne, 2013; Yigermal, 2017). While other studies were done only on particular course which cannot reflect the overall performance of the students (Obadaki \& Omowumi, 2013; Zainal, Yahya \& Rahman, 2014; Okafor, 2011). However, the objective of this study was to assess gender disparity in overall academic performance among undergraduates of College of Medicine and Health Sciences stratified by gender who were graduated in 2017 at Ambo University. Independent t-test was performed to test whether the usual differential pattern of males' predominance in academic achievement has been changed due to affirmative action given to female students. The finding of this study is useful in planning and developing different strategies to enhance female students' retention rate and academic performance.

\section{Methods}

\subsection{Study Design}

In this study, quantitative cross sectional study design was employed to assess gender disparity in academic performance among students of health sciences who were graduated at Ambo University in 2017.

\subsection{Study Period}

The study was conducted from September 20-October 10, 2017.

\subsection{Study Population}

The target population for this study was all regular graduates of 2017 at Ambo University, college of Medicine and Health Sciences consisting 170 undergraduates from Public health, Nursing, Pharmacy and Midwifery programs run under the college.

\subsection{Data Collection Method}

In order to achieve the objective of this study, census survey was conducted to get a full picture of the target population.

\subsection{Data collection instrument}

The data was collected using anonymous self administered questionnaire developed to collect data to achieve the study's objective. The content of the questionnaire includes the socio-demographic characteristics and academic performance indicator variables.

\subsection{Study variables}

\subsubsection{Dependent variables.}

The dependent variables of this study were academic performance indicators:

- Standardized grade 12 Ethiopia higher education entrance examination result out of 700 points the students achieved which was administered by ministry of education and

- Cumulative grade point averages (CGPA) out of 4.00 points they achieved at university in the final year.

\subsubsection{The independent variables}

Independent variables of the study include sex, department, residence, religion and ethnic group of the students. 


\subsection{Stratifying Factor}

The students were classified into two groups based on gender since affirmative action including tutorial classes, life skills training, study skills training; time management training and counseling services have been given to female students in the university to fill gender gap in academic performance.

\subsection{Statistical Analysis}

\subsubsection{Hypothesis formulation}

Two sided hypothesis was formulated to answer the research question: "is there a significant difference in mean CGPA between male and female students?"

$H_{0}:$ There is no difference in mean CGPA between the two groups $\left(\mathrm{H}_{0}: \mu_{1}-\mu_{2}=0\right)$

$H_{1}$ : There is a difference in mean CGPA between th e two groups $\left(\mathrm{H}_{1}: \boldsymbol{\mu}_{1}-\boldsymbol{\mu}_{2} \neq 0\right)$

\subsubsection{Statistical Test}

Independent sample t-test was employed to compare academic performance of two groups of students based on CGPA they achieved at final year. The students were placed into two groups according gender.

Important notations used in the hypothesis test were defined as follow:

- $\quad n_{1}$ refers to number of male students

- $n_{2}$ refers to number of female students

- $\mu_{1}$ refers to population mean CGPA of male students

- $\mu_{2}$ refers to population mean CGPA of female students

- $\bar{X}_{1}$ refers to sample mean CGPA of male students

- $\bar{X}_{2}$ refers to sample mean CGPA of female students

- $\mathrm{S}_{1}^{2}$ refers to sample variance CGPA of male students

- $\mathbf{S}_{2}^{2}$ refers to sample variance CGPA of female students

The significance level $(\alpha)$ of the hypothesis test was set to 0.05 .

\subsubsection{Test statistic}

Under the null hypothesis $\left(H_{0}: \mu_{1}-\mu_{2}=0\right)$ and equal variance assumption, test statistic is given as:

$$
t_{\text {statistic }}=\frac{\bar{X}_{1}-\bar{X}_{2}}{\sqrt{s_{p}^{2}\left(\frac{1}{n_{1}}+\frac{1}{n_{2}}\right)}} \sim t_{\left(n_{1}+n_{2}-2\right)}
$$

Pooled variance is computed as:

$$
S_{p}^{2}=\frac{\left(n_{1}-1\right) S_{1}^{2}+\left(n_{2}-1\right) S_{2}^{2}}{n_{1}+n_{2}-2}
$$

Since the test is two sided, P-value is computed as:

$$
P-\text { value }=2 \times P\left(t_{\left.n_{1}+n_{2}-2\right)}>t_{\text {statistic }}\right) ; \text { where } \mathbf{n}_{1}+n_{2}-2 \text { is degrees of freedom }
$$

Then, P-value is compared with the significance level $(\alpha)$ to suggest the observed difference in mean CGPA between the two groups is significant or not.

\subsubsection{Software Used}

Statistical data analysis was performed using SPSS version 21. Both descriptive and inferential statistical analyses were performed. Socio-demographic and academic performance indicator variables of the study participants were summarized by descriptive statistics. Then, hypothesis test was performed to investigate the mean difference in university entrance examination score and Cumulative Grade Point Average (CGPA) between male and female students. In this particular hypothesis testing research, the effectiveness of affirmative action given to female university students to enhance their academic performance was assessed using independent t-test by comparing 
overall academic achievement of male and female students.

Accordingly, standardized grade 12 Ethiopia higher education entrance examination scores of male students were compared with that of female students to assess gender disparity in academic performance at high school. Similarly, Cumulative Grade Point Average (CGPA) achievements were compared between male and female students to assess gender disparity in academic performance at university. For both academic performance indicators $95 \%$ confidence interval was presented. P-value $<0.05$ was considered to be statistically significant for the hypothesis tests done in this study.

\section{Results}

This part contains the result of the study and presented thoroughly. The questionnaires were distributed to all of the students consisting 170(125 males and 45 females) undergraduates from the four programs. However, only 133(92 male and 41 female) graduates successfully completed and returned the questionnaires, yielding a response rate of $78.2 \%$. Therefore, data from 133 completed questionnaires were used for the analysis in this study.

Socio-demographic summary of the undergraduate graduated at Ambo University, College of Medicine and Health Sciences in 2017 shows that out the total of 133 study participants, female graduates accounted only $30.8 \%$. The study participants comprises 40(30.1\%) Nursing, 42(31.6\%) Public health, 20(15.0\%) Pharmacy and $31(23.3 \%)$ Midwifery department graduates. The result shows that, more than half, $72(54.1 \%)$ of them were from rural residence. Concerning their ethnic group, the study participants classified into 89(66.9\%) Oromo, 29(21.8\%) Amhara and 15(11.3\%) Others. Besides, according to their religion, the participants were further classified into 65(48.9\%) Orthodox, 34(25.6\%) Protestant, 29(21.8\%) Islam and 5(3.8\%) others (table 3.1).

Table 3.1. Socio-demographic summary of undergraduate graduates of 2017, Ambo University College of Medicine and Health Sciences $(\mathbf{N}=133)$

\begin{tabular}{|l|l|l|}
\hline Characteristics & Frequency & percentage \\
\hline Sex & & \\
Male & 92 & $69.2 \%$ \\
Female & 41 & $30.8 \%$ \\
\hline Department & & \\
Nursing & 40 & $30.1 \%$ \\
Public Health & 42 & $31.6 \%$ \\
Pharmacy & 20 & $15.0 \%$ \\
Midwifery & 31 & $23.3 \%$ \\
\hline Birth place & 72 & $54.1 \%$ \\
Rural & 61 & $45.9 \%$ \\
Urban & & \\
\hline Religion & & \\
Orthodox & 65 & $48.9 \%$ \\
Protestant & 34 & $25.6 \%$ \\
Islam & 29 & $21.8 \%$ \\
Others & 5 & $3.8 \%$ \\
\hline Ethnic group & & \\
Oromo & 89 & $66.9 \%$ \\
Amhara & 29 & $21.8 \%$ \\
Others & 15 & $11.3 \%$ \\
\hline
\end{tabular}

\subsection{Descriptive summary of the students' achievement in Academic Performance Indicators}

As can be seen from table 3.2, male undergraduates' average university entrance score was 442.6 with standard deviation of 25.2 compared to 428.5 with standard deviation of 27.1 for female students. In similar manner, male undergraduate graduates' CGPA was 3.29 with standard deviation of 0.41 compared to 2.93 with standard deviation of 0.39 for female students.

Table 3.2. Descriptive summary Academic Performance of undergraduates of 2017, Ambo University College of Medicine and Health Sciences.

\begin{tabular}{|l|l|l|r|r|r|}
\hline Academic Performance indicator & sex & N & Mean & Std. Deviation & Std. Error Mean \\
\hline \multirow{2}{*}{ University entrance examination score } & Male & 92 & 442.63 & 25.17 & 2.62 \\
\cline { 2 - 6 } & Female & 41 & 428.54 & 27.08 & 4.23 \\
\hline \multirow{2}{*}{ C GPA } & Male & 92 & 3.29 & 0.41 & 0.04 \\
\cline { 2 - 6 } & Female & 41 & 2.93 & 0.39 & 0.06 \\
\hline
\end{tabular}




\subsection{Gender disparity hypothesis test in Academic Performance}

As can be seen from table 3.3, normality assumption was checked and Shapiro-Wilk test shows that CGPA distribution for male students was not normal (Shapiro-Wilk statistic $=0.942, \mathrm{df}=92, \mathrm{p}$-value $<0.001$ ) while it is normal for female students (Shapiro-Wilk statistic $=0.982, \mathrm{df}=41, \mathrm{p}$-value $=0.734$ ). Concerning university entrance exam score distributions for male and female students, both of them are not normal (For males: Shapiro-Wilk statistic $=0.922, \mathrm{df}=92$, p-value $<0.001$; females: Shapiro-Wilk statistic $=0.723, \mathrm{df}=41, \mathrm{p}$-value $<0.001)$.

Table 3.3. Test of normality assumption for distributions of academic performance indicators.

\section{Tests of Normality}

\begin{tabular}{|c|c|c|c|c|c|c|c|}
\hline \multirow{2}{*}{ Academic performance indicators } & \multirow[t]{2}{*}{ Gender } & \multicolumn{3}{|c|}{ Kolmogorov-Smirnov $^{\mathrm{a}}$} & \multicolumn{3}{|c|}{ Shapiro-Wilk } \\
\hline & & Statistic & $\mathrm{df}$ & Sig. & Statistic & df & Sig. \\
\hline \multirow{2}{*}{ CGPA } & Male & .103 & 92 & .018 & .942 & 92 & .000 \\
\hline & Female & .079 & 41 & $.200^{*}$ & .982 & 41 & .734 \\
\hline \multirow{2}{*}{ UEES } & Male & .172 & 92 & .000 & .922 & 92 & .000 \\
\hline & Female & .293 & 41 & .000 & .723 & 41 & .000 \\
\hline
\end{tabular}

Abbreviations: $\mathrm{CGPA}=$ Cumulative grade point average; UEES= university entrance examination score

As can be seen from table 3.4, Levene's Test for Equality of Variances shows, variability of university entrance exam score among male students was similar with the variability of female students $(\mathrm{F}=3.459$, $\mathrm{p}$-value= 0.065). Similarly, variability of average cumulative grade point (CGPA) among male students was similar with the variability of female students $(\mathrm{F}=0.066, \mathrm{p}$-value $=0.798)$.

However, test of normality suggests that except for the distribution of CGPA for female students, both academic performance indicators (university entrance examination score and CGPA) distributions violet normality assumption. Even though, the distributions of academic performance indicators in each group violet normality assumption, Central Limit Theorem was taken into consideration since sample size of each group was large enough $(n \geq 30)$

As revealed in table3.4, independent samples t-test results show that there was a significance mean difference between male students' grade 12 exam achievement and female students achievement (Mean difference $=14.1 ; 95 \%$ CI: 4.52-23.67; $\mathrm{t}=2.913, \mathrm{df}=131, \mathrm{p}$-value $=0.004)$. There was also a significant mean difference between male and female students on CGPA achievement at university (Mean difference $=0.36 ; 95 \% \mathrm{CI}: 0.21-0.51 ; \mathrm{t}=4.780, \mathrm{df}=131$, p-value $<0.001)$.

Table 3.4. Independent t-Test of Gender disparity in Academic Performance of the Students

\begin{tabular}{|c|c|c|c|c|c|c|c|c|c|}
\hline \multirow[t]{3}{*}{$\begin{array}{l}\text { Academic } \\
\text { performance } \\
\text { indicator }\end{array}$} & \multicolumn{2}{|c|}{$\begin{array}{l}\text { Levene's Test } \\
\text { for Equality of } \\
\text { Variances }\end{array}$} & \multicolumn{7}{|c|}{ t-test for equality of Means } \\
\hline & \multirow[t]{2}{*}{$\mathrm{F}$} & \multirow[t]{2}{*}{ Sig. } & \multirow[t]{2}{*}{$\mathrm{t}$} & \multirow[t]{2}{*}{ df } & \multirow[t]{2}{*}{$\begin{array}{l}\text { Sig.(2- } \\
\text { tailed) }\end{array}$} & \multirow[t]{2}{*}{$\begin{array}{l}\text { Mean } \\
\text { difference }\end{array}$} & \multirow[t]{2}{*}{$\begin{array}{l}\text { Std. Error } \\
\text { Difference }\end{array}$} & \multicolumn{2}{|c|}{$\begin{array}{l}95 \% \text { CI of the } \\
\text { difference }\end{array}$} \\
\hline & & & & & & & & Lower & Upper \\
\hline $\begin{array}{l}\text { UEES(equal } \\
\text { variance } \\
\text { assumed) }\end{array}$ & 3.459 & 0.065 & 2.913 & 131 & 0.004 & 14.09 & 4.84 & 4.52 & 23.67 \\
\hline $\begin{array}{l}\text { CGPA (equal } \\
\text { variance } \\
\text { assumed) }\end{array}$ & 0.066 & 0.798 & 4.780 & 131 & 0.000 & 0.363 & 0.076 & 0.21 & 0.51 \\
\hline
\end{tabular}

\section{Discussion}

In this study, two important academic performance indicators were used. Standardized grade 12 Ethiopia higher education entrance examination result was used to assess gender disparity the students in academic performance at high school. In order to assess gender disparity in academic performance at university, university based overall examination result measured by cumulative grade point average the students achieved at final year was used.

The purpose of this study was to test gender disparity among undergraduates with regard to academic performance. The attempt was also made to estimate females' graduation rate by investigating gender composition of the graduates. Even though all undergraduate graduates of 2017 from the four programs run under the college of Medicine and Health Sciences were involved in the study, 37 (21.8\%) of them didn't return the questionnaire. Among the 37 non-respondents, $33(89.2 \%)$ of them were male students. Since majority of the non-respondents were male, the findings from the 133 respondents used for analysis overestimated female undergraduate graduates' proportion to be $30.8 \%$. However, the college's graduation endorsement of the year 2017 shows that out of 170 graduates $45(26.5 \%)$ was females. Therefore, the actual female undergraduate graduates' proportion of the college in the year 2017 was only $26.5 \%$. 
This shows that undergraduate female graduates of the college are still underrepresented. Several studies reported factors that have affected females' higher education. Females' low enrollment rate due to early and forced marriage as a result of long-standing cultural misconception is mentioned as major factor for low proportion of female graduates (Federal Democratic Republic of Ethiopia Ministry of Education, 2010). Gender stereotypes that give preference to boys over girls in access to education is also among other factors that have reduced female graduates proportion (Swedish Agency for Development Evaluation Reports, 2010; Dea, 2016). Additionally, studies shows that females' drop out due to lack of special support from educational institutions has reduced the proportion of female graduates (Olkaba, 2013; Mersha, Bishaw \& Tegegne, 2013; Tiruneh \& Petros, 2014). Therefore, gender composition gap observed among undergraduates of Ambo University, college of Medicine and Health Sciences could be due to the combined effect of these reasons.

Independent t-test result shows that female undergraduate graduates were joined the university with lower university entrance examination score (Mean=428.5, $\mathrm{SD}=27.1)$ compared to their male counterparts (Mean=442.6, $\mathrm{SD}=25.2$ ). Their achievement mean difference at grade 12 was found to be statistically significant (Mean difference $=14.1 ; 95 \%$ CI: 4.52-23.67; $\mathrm{t}=2.913, \mathrm{df}=131, \mathrm{p}$-value $=0.004)$. Similarly, their academic performance at the University was assessed based on CGPA achievement at graduation. The CGPA analysis result shows that female undergraduate graduates achieved lower CGPA (Mean=2.93, SD=0.39) than male undergraduates $(\mathrm{Mean}=3.29, \mathrm{SD}=0.41)$. Their academic achievement mean difference in CGPA was also found to be statistically significant (Mean difference $=0.36 ; 95 \% \mathrm{CI}: 0.21-0.51 ; \mathrm{t}=4.780, \mathrm{df}=131, \mathrm{P}$-value $<0.001$ ). The gender disparity observed in this study among undergraduates CGPAs, with male achieving higher final degree CGPA is similar to findings of (Olkaba, 2013; Eshetu, 2015; Yigermal, 2017). However, several researchers found result that reveals female graduates performed significantly better than males (Obadaki \& Omowumi, 2013; Zainal, Yahya \& Rahman, 2014; Khan \& Nawaz, 2012; Ahmad, Pervaiz \& Aleem, 2015; Madara \&Namango, 2016; Tarabashkina \& Lietz, 2011). These inconsistence findings might be due to the differences of study settings and design.

Numerous studies done on the similar topic have revealed different factors that have contributed to academic under-achievement in females. Among other factors, lack of proper implementation of higher education policies and strategies in universities is reported by most earlier studies (Mersha, Bishaw \& Tegegne, 2013; Tiruneh \& Petros, 2014; Tenaw, 2018; Federal Democratic Republic of Ethiopia Ministry of Education, 2014). Some studies mentioned that females' low self perception about their ability is also among the factors that have affected females' academic performance (Mersha, Bishaw \& Tegegne, 2013; Tiruneh \& Petros, 2014; Tenaw, 2018). A study done among medical students revealed that stress has negative impact on academic performance (Melaku \& Mossie, 2015). It is highly likely that female students suffer more from stress due to sexual harassment (Mersha, Bishaw \& Tegegne, 2013).

In addition to all these factors, other researchers showed that high school academic background is considered to be significant predictor of university academic performance (Afzal, Ali, Khan \& Hamid,2010; Gardy \& Akbay, 2015; Muhammedhussen, 2016). In this particular study, female students' high school performance was significantly lower than male students' performance. Therefore, their high school performance could be one of the reasons for the gender disparity pattern with female students achieving lower cumulative grade point average (CGPA) at university. Thus, female students' under achievement compared to male students is not disappeared due to affirmative action intervention provided to female students in the university.

\section{Conclusion and Recommendations}

\subsection{Conclusion}

The findings of this study show that there were significant gender disparities among undergraduate graduates of the year 2017 in Ambo University, College of medicine and health sciences. According to their high school back ground, female students joined the university with significantly lower university entrance examination score compared to male students. Similarly, female students' academic performance measured by cumulative grade point average they achieved at the university was also significantly lower than male students' academic performance. Moreover, female undergraduate graduates were underrepresented in the college accounting only $26.5 \%$ of the graduates in the year 2017.

The empirical evidence of this study shows that gender disparity pattern of female students academic under achievement at university was not changed. This gender disparity pattern in academic performance observed in this study may be due to lower self-concept, stress due to sexual harassment, gender stereotypes, lower financial and emotional support female students get from their families than male students and lower university entrance exam score female students achieved at grade 12 compared to male students.

The implication of the result of this study indicates that, the presence of affirmative action intervention for university female students couldn't eliminate gender composition gap at graduation and academic performance. The reason might be the absence of monitoring and evaluation of the implementation of the affirmative action. Similarly, active learning and continuous assessment might not be properly implemented in addressing class diversities which affect learning outcomes. If these gaps are not tackled, they further affect women's participation 
and competition in different health care service provider institutions and higher education institutions.

\subsection{Recommendations}

Based on the findings and conclusions of the study, the following recommendations are forwarded. Each program run under the college should properly implement affirmative action intervention to enhance female students' retention rate and academic performance. It was recommended that gender office of the college should develop strategy to effectively supervise the implementation of the affirmative action intervention as it was intended. Furthermore, College of Medicine and Health Sciences should give on job training for instructors continuously on active learning methods implementation to address class diversities which affect learning outcomes. In addition, further research with mixed method design is needed to identify factors influencing the academic performance of female students in the university.

\section{Acknowledgment}

I am very grateful to Samuel Leyikun, educational quality and audit team leader of department of linguistics, Ambo University for his technical assistance in language edition for this study.

\section{References}

1. Afzal H, Ali I, Khan A.M, Hamid K. (2010). A Study of University Students' Motivation and Its Relationship with Their Academic Performance. International Journal of Business and Management, 5(4), 80-88.

2. Ahmad M.R, Pervaiz M.K, Aleem M. (2015). A Comparative Study Of The Factors Affecting The Male And Female Students' Academic Performance In Higher Education (A Case Of Government College University, Lahore). European Scientific Journal, 11(7), 429-436.

3.Dea M.(2016). The Prospectus, Challenges and Causes of Gender Disparity and its Implication for Ethiopia's Development: Qualitative Inquiry. Journal of Education and Practice, 7(4), 2437.

4. Eshetu A.A. (2015). Gender Disparity analysis in academic achievement at higher education preparatory schools: Case of South Wollo, Ethiopia. AcademicJournals, 10(1), 50-58.

5. Farhan S, Khan I.(2015). Impact Of Stress, Self-Esteem and Gender Factor On Students' Academic Achievement. International Journal on New Trends in Education and Their Implications, 6(2), 143-156.

6. Federal Democratic Republic of Ethiopia Ministry of Education (2010). National Girls' Education Strategy. Retrieved from: http://info.moe.gov.et/gendocs/MOEGE.pdf.

7. Federal Democratic Republic of Ethiopia Ministry of Education (2014). Gender Strategy for the Education and Training Sector. Retrieved from: http://www.moe.gov.et/documents/20182/36315/GENDER+STRATEGY.pdf/b9e68a15-bc9e-4930-a5d2$1 \mathrm{c} 1981 \mathrm{ca} 264 \mathrm{c}$

8. Federal Democratic Republic of Ethiopia Ministry of Education(2015/16). Statistics Annual Abstract, Retrieved from: http://www.moe.gov.et/documents/20182/0/ESSA+2008+E.C+\%282015-2016+G.C\%29/9ae1928721c9-431b-b53a-d4edfb5fb997?version=1.0.

9. Fergusson DM, Horwood LJ. (1997). Gender differences in educational achievement in a New Zealand birth cohort. New Zealand Journal of Educational Studies, 32(1), 83-96.

10. Gardy M.H.S, Akbay C. (2015). Academic Performance of Undergraduate Students at Soran University in Northern Iraq. International Journal of Advanced Research in Education \& Technology (IJARET), 2, 94-97.

11. Islam M.M. (2014). Factors Influencing the Academic Performance of Undergraduate Students in Sultan Qaboos University in Oman. Journal of Emerging Trends in Educational Research and Policy Studies, 5(4), 396-404.

12. Issahaku P.A. (2017). An Investigation of Factors that Influence the Academic Performance of Undergraduate Students of Public Universities in Ghana. Mediterranean Journal of Social Sciences, 8(3), 259-266.

13. Kenney-Benson G.A, Pomerantz E.M, Ryan A.M, Patrick H.(2006). Sex Differences in Math Performance: The Role of Children's Approach to Schoolwork. Developmental Psychology, 42(1), 11-26.

14. Khan B.B, Nawaz R, Chaudhry K.M, Hyder A.U, Butt T. M. (2012). Evaluation of Comparative Academic Performance of Undergraduate Students at University Level. Journal of Animal \& Plant Sciences, 22(3), 798-801.

15. Kheswa J.G. (2014). Exploring the Causal Factors and the Effects of Sexual Harassment on Female Students at the Universities in Africa. An Overview. Mediterranean Journal of Social Sciences, 5(20), 2847-2852.

16. Madara D.S, Namango S.S. (2016). Longitudinal Comparative Study: Females' vs. Males' Graduation Outcomes in Undergraduate Engineering. Journal of Education and Practice, 7(30), 9-23.

17. Mamo H, Gosa G, Hailu B. (2017). Perception of University Female Students on Factors Affecting Their Academic Performance and Competency: A Study from Dire Dawa University, Ethiopia. Science Journal of 
Education, 5(5), 211-215.

18. Melaku L, Mossie A, Negash A. (2015). Stress among Medical Students and Its Association with Substance Use and Academic Performance. Journal of Biomedical Education, 1(1), 1-9.

19. Mersha Y, Bishaw A, Tegegne F.(2013). Factors Affecting Female Students' Academic Achievement at Bahir Dar University. Journal of International Cooperation in Education, 15(3), 135-148.

20. Muhammedhussen M. (2016). Determinants of Economics Students' Academic Performance: Case Study of Jimma University, Ethiopia. International Journal of Scientific and Research Publications, 6(1), 566-571.

21. Núñez-Peña M.I, Suárez-Pellicioni M, Bono R.(2016). Gender differences in test anxiety and their impact on higher education students' academic achievement. 2nd International Conference on Higher Education Advances. HEAd'16, 21-23 June 2016, València, Spain, P.154 - 160.

22. Obadaki Y.Y, Omowumi Y.K.(2013). Comparative study of gender difference performance in geography: A case study of some selected schools in Zaria inspectorate division of Kaduna state, Nigeria. Educational Research and Review, 8(5), 179-185.

23. Okafor C.A. (2011). Academic Performance of Male versus Female Accounting Undergraduate Students: Evidence from Nigeria. Higher Education Studies, 1(1), 9-17.

24. Olkaba T.T.(2013). Disparity in Academic Achievement in Selected Colleges of Teachers Education in Oromia Region. Ethiop. J. Educ. \& Sc., 9(1), 15-38.

25. Puju J.A, Netragaonkar Y.D. (2014). Self Concept And Academic Achievement Of Under-Graduate Male And Female Students Of Kashmir. Scholarly Research Journal For Humanity Science and English Language, $1(5), 670-676$.

26. Swedish Agency for Development Evaluation Reports (2010). Gender equality in and through education. Retrieved from: http://www.oecd.org/derec/sweden/48350382.pdf.

27. Tarabashkina L, Lietz P. (2011). The impact of values and learning approaches on student achievement: Gender and academic discipline influences. Issues in Educational Research, 21(2),210-231.

28. Tenaw A. (2018). Factors Affecting the Academic Performance of Female Students at Higher Education in Ethiopia. Global Journal of HUMAN-SOCIAL SCIENCE: G Linguistics \& Education, 18(1), 24-28.

29. Tiruneh, W. A., and Petros, P.(2014). Factors affecting female students' academic performance at higher education: The case of Bahir Dar University, Ethiopia. African Educational Research Journal, 2(4), 161-166.

30. Yigermal M.E. (2017). The Determinants of Academic Performance of Under Graduate Students: In the Case of Arba Minch University Chamo Campus. Advances in Sciences and Humanities, 3(4), 35-42.

31. Zainal R., Yahya R., Rahman K.A.(2014). Influences of gender on academic achievement of Fiber Optic Communication System: An experience of Politeknik Merlimau Melaka . IOSR Journal Of Humanities And Social Science (IOSR-JHSS), 19(8), 108-111. 